\title{
Formulation and Characterization of Gastroretentive Discs Containing Famotidine
}

\author{
Jignyasha Amitkumar Raval ${ }^{1 *}$ and Madhabhai M.Patel ${ }^{2}$ \\ ${ }^{1}$ S. K. Patel College of Pharmaceutical Education and Research; Ganpat University; Kherva; Gujarat - India. ${ }^{2}$ Kalol \\ Institute of Pharmacy; Gujarat Technical University; Kalol; Gujarat - India
}

\begin{abstract}
In this work a different type of formulation, as disc, containing a selected mucoadhesive polymer, fillers, and binders were investigated for their potential as a mucoadhesive gastroretentive delivery system to deliver famotidine in the stomach. Various types of hydrophilic diluents were evaluated for their swelling and mucoadhesive property and one (polyvinylpyrrolidone, PVP) was selected to combine with the selected mucoadhesive polymer (polyethylene oxide, PEO). Discs with different ratios of PEO and PVP were prepared and evaluated for swelling, dissolution, and mucoadhesion. The swelling property of the discs increased as the concentration of PEO was increased and also did the mucoadhesion. These discs retained their integrity and adherence onto gastric mucosa for more than 10 $h$ under in-vitro conditions. The PEO, in combination with PVP, yielded a non-disintegrating type mucoadhesive dosage form which was suitable for gastroretentive applications to achieve the desired release profile of the drug.
\end{abstract}

Key words: mucoadhesion; discs; gastroretentive; polyethylene oxide; polyvinylpyrrolidone

\section{INTRODUCTION}

Famotidine is a histamine $\mathrm{H}_{2}$-receptor antagonist. It is widely prescribed in the treatment of gastric ulcers, duodenal ulcers, Zollinger-Ellison syndrome, and gastroesophageal reflux disease in doses ranging from 10 to $80 \mathrm{mg}$ (Reynolds). The low bioavailability (40-45\%) and short biological half-life (2.5-4.0 h) of famotidine following oral administration favors the development of a sustained release formulation. The absorption of drugs through the gastrointestinal tract is a complex procedure and varies due to the presence of loose junctions and active transporters showing absorption only in the upper part of the gastrointestinal tract, especially the proximal part of small intestine (Ali et al., 2006, 2007; Basak et al., 2007; Dave et al., 2004; Marathe et al., 2000; Raval et al., 2007) Gastroretentive systems can remain in the gastric region for several hours, and therefore, significantly prolong the gastric residence time of such drugs improving their bioavailability (Davis, 2005; Moes, 1993; Streubel et al., 2006, 2006a). Several formulations have been designed, including altered density systems (Jaimini et al., 2007; Rouge et al., 1998; Streubel et al., 2002, 2003; Talukder and Fassihi, 2004; Whitehead et al., 1998), expandable swelling systems (Groning et al., 2006; Gröninga et al., 2007; Klausner et al, 2003; Deshpande, 1997), and bioadhesive/ mucoadhesive systems (Chavanpatil et al., 2006; Huang et al., 2000; Ponchel and Irache, 1998; Tao and Desai, 2005).

It has been reported that the oral treatment of gastric disorders with $\mathrm{H}_{2}$ receptor antagonist like

*Author for correspondence: jignyasha26@yahoo.com 
famotidine or ranitidine used in combination with antacids promotes the local delivery of these drugs to the receptor of parietal cell wall. Local delivery also increases the stomach wall receptor site bioavailability and increases the efficacy of drugs to reduce acid secretion. Hence, this principle may be applied for improving the systemic as well as local delivery of famotidine, which would efficiently reduce gastric acid secretion (Coffin and Parr, 1995).

Mucoadhesive systems explore the adhesive properties of some polymers on the mucus linings of various biological tissues for increasing the residence time of delivery devices in a specific biological location. Such increase in residence time prompts to enhance the bioavailability of drugs (Davis, 2005; Huang et al., 2000). In addition to mucoadhesion and swelling, mucoadhesive system should also possess sufficient mechanical strength in order to withstand the mechanical forces which are created by digestive activities of the stomach. Although a non-disintegrating and swelling type tablet formulation made with a mucoadhesive polymer can overcome the mechanical issues, a concern with such systems is the fate of the formulation matrix after drug release. Undigested materials in the stomach will either be expelled out to the mouth for further grinding by reflux activities or the house keeper wave of stomach will push it through the relaxed and open pylorus to the intestine. Complete dissolution or erosion of the formulation matrix in a timely manner is, therefore, important for gastroretentive dosage forms. Studies have reported that PEO has mucoadhesive properties which may assist prolonging the gastric residence time (Dhawan et al., 2005). The swelling characteristics of polymers were found to contribute to mucoadhesion. The swelling behavior of PEO hydrogels is not influenced by the $\mathrm{pH}$ or ionic strength of medium and, therefore, showed a similar mucoadhesive trend in acidic and neutral $\mathrm{pH}$ environments. The $\mathrm{pH}$ independent swelling and mucoadhesion behavior of PEO makes it a reliable polymer for mucoadhesion in the stomach. Such systems are expected to reside in the stomach for relatively longer duration than the solution dosages, disintegrating type solid formulations, and other conventional formulations, improving the absorption of drugs that show preferential absorption in the stomach or upper part of intestine. The objective of the present study was to formulate a slow dissolving mucoadhesive matrix using PEO in combination with different hydrophilic diluents and evaluate the dissolution, swelling, in vitro gastric retention properties of polymeric discs for the delivery of famotidine in the stomach.

\section{MATERIALS}

Famotidine was obtained as gift sample from Torrent Pharmaceuticals Ltd., Indrad, India. Three different grades of polyethylene oxides (Polyox WSR 301, polyox WSR coagulant, and polyox WSR 303, PEO grades) were obtained from DOW chemical company, NJ, USA. Polyvinyl pyrollidone K- 30 (PVP K- 30) and Polyvinyl pyrollidone K- 90 (PVP K- 90) were obtained from Alembic, Vadodara, India. Others chemicals were purchased from S.D. Fine Chemicals Ltd., Mumbai, India. All ingredients were analytical grade.

\section{METHODS}

\section{Preparation of Famotidine Discs}

Different discs were prepared with $100 \%$ hydrophilic diluents such as, PEO 301, PEO Coagulant, PEO 303, PVP K30, PVP K90, MCC, DCP and starch and evaluated. Different formulations were prepared by direct compression technique considering a batch size of 100 discs. Weighed quantity of drug, matrix polymer and different hydrophilic diluents were passed though 80 mesh sieve. The powders were mixed thoroughly using geometric method. Talc and magnesium stearate were finally added as glidant and lubricant, respectively. Blending was carried out using lab scale V-blender of $100 \mathrm{~g}$ capacity (Orchid AP-01, India) for $30 \mathrm{~min}$. The blend was compressed using multipunch tablet compression machine (a lab press, Cadmach Csi 670, India) under a pressure of $25 \mathrm{~kg} / \mathrm{cm} 2$. Each disc contained $40 \mathrm{mg}$ of famotidine and other pharmaceutical ingredients as listed in Table 1. The discs were round and flat with an average diameter of $8.2 \pm 0.1 \mathrm{~mm}$, a hardness of $4-6$ $\mathrm{kg} / \mathrm{cm} 2$ and a thickness of $2.5 \pm 0.1 \mathrm{~mm}$. Evaluation of the formulation was also done for the weight variation test, drug content, mucoadhesion force and in vitro gastroretention time. 
Table 1 - Composition of the famotidine discs.

\begin{tabular}{lcccccccc}
\hline Ingredients & FP1 & FP2 & FP3 & FP4 & FP5 & FP6 & FP7 & FP8 \\
\hline Famotidine & 40 & 40 & 40 & 40 & 40 & 40 & 40 & 40 \\
PEO 303 & 10 & 20 & 40 & 50 & 60 & 80 & 90 & 100 \\
PVP K 90 & 90 & 80 & 60 & 50 & 40 & 20 & 10 & 0 \\
Mg Stearate & 1.5 & 1.5 & 1.5 & 1.5 & 1.5 & 1.5 & 1.5 & 1.5 \\
Talc & 3.5 & 3.5 & 3.5 & 3.5 & 3.5 & 3.5 & 3.5 & 3.5 \\
\hline
\end{tabular}

* The weights of all ingredients mentioned in the above table are in $\mathrm{mg}$.

\section{Characterization of famotidine discs \\ Integrity time}

The time for which the disc remained intact was determined in $0.1 \mathrm{~N} \mathrm{HCl}$. Discs $(\mathrm{n}=3)$ were immersed in $100 \mathrm{~mL}$ of $0.1 \mathrm{~N} \mathrm{HCl}$ in glass beakers and stirred at $100 \mathrm{rpm}$ using a overhead stirrer, maintaining the temperature at $37 \pm 0.5^{\circ} \mathrm{C}$ using hot plate. Each beaker was carefully observed for erosion or collapse of the discs. The time required for retaining atleast $25 \%$ of the original dimension of discs was recorded and used as an indicative parameter to compare different formulations.

\section{Swelling study}

Swelling of discs was determined by immersion method. Discs $(n=3)$ were immersed in glass Petridish containing $10-15 \mathrm{~mL}$ of $0.1 \mathrm{~N} \mathrm{HCl}$ at room temperature. The radius of each disc was measured without disturbing Petri dish. The diameter of the discs was determined and compared with that of the original diameter to calculate the percent of swelling. The following equation was used for calculating the swelling of discs.

Swelling $\%=[($ Final diameter - Initial diameter $) /$ Initial diameter] x 100

\section{In vitro gastroretention time}

The in vitro gastroretention time studies were performed $(n=3)$ after application of discs on freshly cut rat stomach mucosa. The mucosa was fixed on a glass slide and kept in a slanting position in the beaker. A side of each disc was wetted with $50 \mu \mathrm{L}$ fluid and was attached to the mucosa by applying a light force with a fingertip for 20 seconds. The beaker was filled with $900 \mathrm{~mL}$ of simulated gastric fluid and kept at $37^{\circ} \mathrm{C}$; after two minutes, a stirring rate of $100 \mathrm{rpm}$ was applied to simulate the stomach. Disc behavior and gastroretention time were monitored until complete detachment or dissolution occurred.

\section{In vitro Mucoadhesion Force}

For this study, rat stomach mucosal membrane was used. A simple apparatus was devised to measure the minimum detachment force. A piece of mucosal membrane $(2.0 \mathrm{~cm} \times 1.5 \mathrm{~cm})$ removed from newly sacrificed rat was adhered to a piece of glass, which was fixed on a plank and the plank was assembled with a little crown block. After hydrating the mucosa with $20 \mu \mathrm{l}$ of distilled water, the disc was brought into contact with the mucosa by applying $200 \mathrm{~g}$ for $2 \mathrm{~min}$. After the initial contact, the disc was encircled by a firm plastic ring which fastened a light plastic beaker through the crown block. Next, water was dropped into the beaker at a speed of $2 \mathrm{ml} \cdot \mathrm{min}^{-1}$ until the disc and membrane were pulled apart by the gravity of water. The beaker containing water was weighed and the minimum detachment force was calculated accordingly. The study was approved by the Institutional Animal Ethics Committee of Ganpat University. The detachment force in $g$ was transformed into $\mathrm{N}$ by using a conversion factor ( 1 $\mathrm{G}=0.009806 \mathrm{~N}$ ). The test was performed at room temperature, and the mean of three measurements was used as the mucoadhesive strength of the discs. The thickness of stomach mucosa employed in experiments ranged from 1.3 to $2.5 \mathrm{~mm}$.

\section{In vitro Dissolution Studies}

The release rate of famotidine from mucoadhesive discs $(n=3)$ was determined using United State Pharmacopoeia (USP) XXIV dissolution testing apparatus II (paddle method). The dissolution test was performed using $900 \mathrm{ml}$ of $0.1 \mathrm{~N} \mathrm{HCl}$ at $37 \pm$ $0.5^{\circ} \mathrm{C}$ and $50 \mathrm{rpm}$. A sample $(10 \mathrm{ml})$ of the solution was withdrawn from the dissolution apparatus hourly for $8 \mathrm{~h}$, and the samples were replaced with fresh dissolution medium. The samples were filtered through a $0.45 \mu$ membrane filter and diluted to a suitable concentration with $0.1 \mathrm{~N} \mathrm{HCl}$. Absorbance of these solutions was measured at $265 \mathrm{~nm}$ using a Shimadzu UV-1700 UV/Vis double beam spectrophotometer. Cumulative percentage of drug release was calculated using an equation obtained from a standard curve. The drug in $0.1 \mathrm{~N} \mathrm{HCl}$ followed 
Beer - Lambert's law in the range of $10-30 \mu \mathrm{g} / \mathrm{ml}$ with correlation co-efficient of 0.998 .

\section{Kinetics of Drug Release}

The dissolution profile of the best batch was fitted to various models such as zero-order, first-order, Higuchi (Higuchi, 1963), Hixon-Crowell (Hixon and Crowell, 1931), Korsmeyer and Peppas (Korsmeyer and Gurny, 1983; Peppas, 1985; Harland, et al., 1988), and Weibull models (Langenbucher, 1972; Goldsmith, et al., 1978) to ascertain the kinetic modeling of drug release. The least value of sum of square of residuals (SSR) and Fishers ratio $(F)$ were used to select the most appropriate kinetic model (Bamba and Puisieux, 1979).

\section{Stability study}

Gastro retentive discs of famotidine formulated were subjected to accelerated stability studies in Aluminum / Aluminum pouch pack. Dose dumping and failure of mucoadhesion are probable effects anticipated during the stability study of such dosage forms. The discs were charged for accelerated stability studies at $40^{\circ} \mathrm{C}$ and $75 \% \mathrm{RH}$ for three months in a stability chamber. Mucoadhesion force, in vitro gastroretention time, integrity time, drug dissolution profile and drug content of exposed sample was carried out.

\section{In vivo study}

The optimized formulation was further modified to incorporate barium sulphate as X-Ray opaque substance, replacing the drug with barium sulphate made initial formulation trials. The optimized formulation containing barium sulphate $40 \mathrm{mg}$, while the remaining ingredients in the same quantities as mentioned above, showed satisfactory ex vivo mucoadhesion. Hence, this formulation was further selected for in vivo evaluation. The quantity of incorporated barium sulphate was detectable in X- Ray photographs. The study was carried out by administering the gastroretentive discs to human volunteer in the fasting state along with $250 \mathrm{ml}$ of water. A light meal was given to volunteer $2 \mathrm{~h}$ after administration of the discs to evaluate effect of food of gastroretentive property. X - Ray photographs were taken after $1 \mathrm{~h}, 3 \mathrm{~h}$ and $8 \mathrm{~h}$ to monitor position of the disc in human gastrointestinal tract. The study was approved by the Institutional Ethics Committee of Ganpat University.

\section{RESULTS AND DISCUSSIONS}

Different discs were prepared with $100 \%$ hydrophilic diluents (PEO 301, PEO coagulant, PEO 303, PVP K30, PVP K90, MCC, DCP and starch). These discs were evaluated for the integrity, mucoadhesion force and swelling \%. The results are shown in Table 2. Discs made of different grades of polyox were physically stable for more than $6 \mathrm{~h}$ in $0.1 \mathrm{~N} \mathrm{HCl}$ at $37^{\circ} \mathrm{C}$, and exhibited higher mucoadhesion on the gastric mucosa compared to all other excipients. Although more than $30 \%$ of the initial dimension of all PEO discs were retained for about $6 \mathrm{~h}$ in $0.1 \mathrm{~N} \mathrm{HCl}$, the extent of dissolution of discs containing polyox WSR 301 and WSR coagulant grades of PEO were higher than that of polyox WSR 303. Polyox WSR 303 showed the highest adhesive strength $(1.78 \mathrm{~N})$ amongst all the grades of PEO and other ingredients. Better retention and mucoadhesion of discs containing WSR 303 grade of PEO could be attributed to its higher molecular weight (Dhawan et al., 2005). During the process of mucoadhesion, mucoadhesive polymers undergo wetting, swelling, and interdiffusion or interpenetration into the mucus or epithelial surface. In this process, polymers with optimum molecular weights are believed to make strong entanglements and reside in the application site for prolonged period of time (Huang et al., 2000).

Among the other excipients screened, only PVP discs retained their structure for more than $55 \mathrm{~min}$. Excipients such as microcrystalline cellulose, dicalcium phosphate, and starch either dissolved completely or disintegrated in $0.1 \mathrm{~N} \mathrm{HCl}$ quickly. None of the excipients showed any significant level of mucoadhesive interaction with the gastric mucosa which was much predictable.

Incorporation of such rapidly dissolving or disintegrating and poorly mucoadhesive excipients could substantially reduce the retentive and adhesive properties of gastroretentive formulations. PVP is a nonirritant material and is not absorbed from the GI tract (Mahalingam et al., 2009). It is extensively used as a tablet binder, thickening, suspending, and stabilizing agent in oral formulations. Among two different molecular grades of PVP screened, K-90 showed about fourfold slower disintegration and two-fold higher mucoadhesive forces. The rate at which the erosion of various grades of PVP takes place is generally controlled by the viscosity of the resulting solution, which is primarily controlled by 
the molecular weight. High molecular weight grades of PVP offer higher binding capacity. The molecular weight of PVP K-90 is almost 20-fold higher than PVP K-30. This ought to be reason for slow dissolution of PVP K-90 discs. Binding and sticking properties of PVP also contribute to the mucoadhesion. Also, the high plastic deformation property of PVP makes it suitable as a binder-filler for direct compression.

PEO discs showed highest mucoadhesion in this study, and did not dissolve in $0.1 \mathrm{~N} \mathrm{HCl}$ for about $6 \mathrm{~h}$. In contrary, PVP K-90 showed relatively lower mucoadhesion than PEO discs $(0.32 \pm 0.02$ $\mathrm{N}$ ), with complete erosion within $3 \mathrm{~h}$. PVP may not provide additional mucoadhesion to discs, but may serve as a modulator for the dissolution of the PEO matrix and avoid the issues of excessive residence in the stomach. Discs made with PEO showed gradual swelling in $0.1 \mathrm{~N} \mathrm{HCl}$, whereas PVP discs did not show swelling due to its dissolution characteristics. The extent of swelling shown by PEO discs after 1, 3, and $6 \mathrm{~h}$ was 46.34 , 89.02 , and $131.71 \%$, respectively.

During the study on checking the integrity maintenance of the discs formulated with different proportions of PEO and PVP, it was found that incorporation of about 7\% PEO into PVP matrix did not improve the swelling property or delay the dissolution of discs; on the other hand, the discs disintegrated within the first two hours with a mucoadhesion force of $0.28 \mathrm{~N}$. Increasing the content of PEO above 25\%, however, showed marked changes in swelling and dissolution properties. The swelling of discs that were formulated with different proportions of PEO and PVP are shown in Figure 1.

The swelling of discs containing approximately $70 \%$ PEO after $6 \mathrm{~h}$ was $114.81 \%$, and the integrity time increased to $10.56 \mathrm{~h}$. The integrity time, mucoadhesion and gastroretention time of PEOPVP discs are shown in Table 2. The mucoadhesive strength of the PEO 303 disc was $1.78 \pm 0.04 \mathrm{~N}$, whereas PVP K-90 discs yielded a mucoadhesive strength of $0.32 \pm 0.02 \mathrm{~N}$. Incorporation of PEO into a PVP matrix gradually increased the mucoadhesive strength of the discs. Mucoadhesion of PVP discs increased linearly as PEO content was increased $\left(\mathrm{R}^{2}=0.987\right)$. Such a linear relationship between the polymer content and mucoadhesion provides a basis in designing the systems with predictable mucoadhesion and dissolution properties. The in vitro gastroretentive time of discs increased significantly with an increase in PEO content, which was mainly due to the increase in the mucoadhesive strength. PEOPVP discs did not detach from the gastric mucosa throughout the duration of the study and dissolved completely into the surrounding medium at different time intervals. The in vitro gastric residence of all the batches were in an increasing order with lowest seen in batch FP1 $1.28 \mathrm{~h}$ to the maximum in batch FP8 $10.19 \mathrm{~h}$.

The in vitro dissolution study was performed to evaluate the characteristic of controlling the drug release from the discs. Based on the release profiles (Figure 2), the results of higher concentrations of PEO were much satisfying than those of higher concentrations of PVP. In case of batches FP1 and FP2, it was found that due to the disintegration of discs by the end of two hours, it led to burst effect (100\% drug release).

An increase from 13 to $27 \%$ of PEO made drastic change in the rate of drug release. The first hour drug release decreased from 48.89 to $38.65 \%$. At the same time, a significant difference that was obtained was that the integrity of the formulation remained for more than $5 \mathrm{~h}$, and there wasn't complete disintegration of the discs. These alterations led to a controlled release of the drug for 7-8 h. In case of batch FP4 where equal amounts of both PEO and PVP were taken, it was found that though the integrity of the formulation was obtained by the concentration of PEO, the drug release was not slowed down to the extent as aimed because of the disintegrating effect of PVP which increased the erosion of the formulation, and hence, higher drug release (similarity factor 37.34). Incorporation of more than $40 \%$ PEO (batches FP5 to FP8) gave release profiles similar to that of theoretical profile with similarity factor greater than 50 (i.e. 66.25, 78.28, 67.87 and 63.72, respectively). The basic requirement of the initial concentration release was almost achieved in the batches FP5 to FP8, ie., 23.89, 21.15, 20.58, and $19.37 \%$, respectively. Looking to the criteria aimed to have more than $90 \%$ drug release from the formulation in $8 \mathrm{~h}$, batch FP8 was excluded from consideration. From among the batches FP5, FP6 and FP7, FP6 and FP7 showed integrity and gastroretention for more than $8 \mathrm{~h}$ and very good mucoadhesion force. Based on the data, batch FP6 was selected as the best batch which stayed intact for about $9.21 \mathrm{~h}$, having gastroretention time of $8.92 \mathrm{~h}$, and a swelling percent of $108.64 \%$, along with a similarity factor of 78.28. 


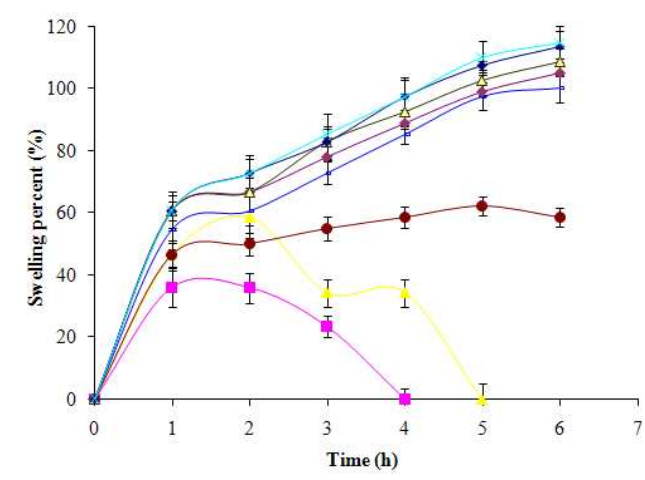

Figure 1 - Swelling study of formulation batches $(\mathrm{n}=3)(-\square)$ FP1 $\left(\square-\square^{-}\right.$FP2 (- $\left.\square\right)$ FP3

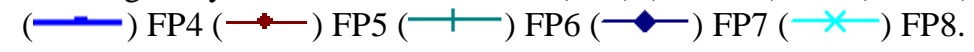

Table 2 - Evaluation data of formulated discs.

\begin{tabular}{cccc}
\hline Formula code & Integrity time $(\mathbf{h})$ & Mucoadhesion force $(\mathbf{N})$ & In vitro gastroretention time (h) \\
\hline FP1 & $1.58 \pm 0.15$ & $0.28 \pm 0.01$ & $1.28 \pm 0.24$ \\
FP2 & $2.03 \pm 0.23$ & $0.46 \pm 0.03$ & $1.93 \pm 0.43$ \\
FP3 & $5.29 \pm 0.27$ & $0.61 \pm 0.05$ & $5.01 \pm 0.27$ \\
FP4 & $5.86 \pm 0.48$ & $0.82 \pm 0.04$ & $5.52 \pm 0.41$ \\
FP5 & $7.63 \pm 0.14$ & $0.97 \pm 0.03$ & $7.24 \pm 0.33$ \\
FP6 & $9.21 \pm 0.29$ & $1.17 \pm 0.02$ & $8.92 \pm 0.26$ \\
FP7 & $9.87 \pm 0.31$ & $1.48 \pm 0.04$ & $9.47 \pm 0.31$ \\
FP8 & $10.56 \pm 0.63$ & $1.63 \pm 0.01$ & $10.19 \pm 0.34$ \\
\hline
\end{tabular}

* Values are the mean $\pm \mathrm{SD} ; n=3$.

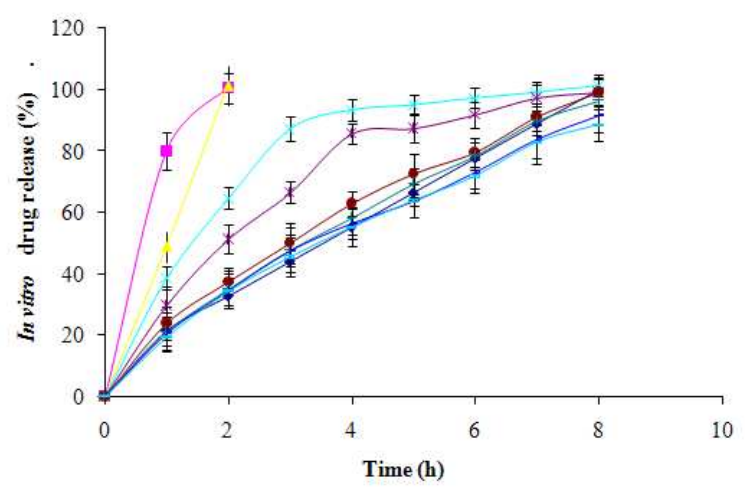

Figure 2 - Drug release patterns of batches FP1 to FP8. $(n=3)(-\smile)$ theoretical profile $(-\square)$

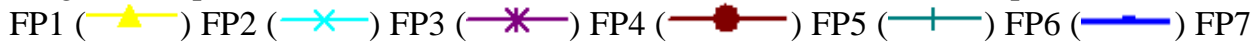
$(-)$ FP8.

\section{Kinetics of Drug Release}

The dissolution profile of the optimized batch was fitted to various models, as mentioned above, to ascertain the kinetic modeling of drug release. The least value of sum of square of residuals (SSR) and Fishers ratio $(F)$ were used to select the most appropriate kinetic model. Korsmeyer-Peppas model showed least sum of square of residuals $(\mathrm{SSR}=4.21)$ and Fischer's ratio $(F=0.7)$. The mechanism of famotidine release from the formulated batch was by anamolous non-fickian diffusion, i.e., diffusion coupled with erosion (kinetic exponent, $\mathrm{n}=0.736$ ).

\section{Stability study}

The similarity factor was calculated for comparison of dissolution profile before and after the stability studies. The $f_{2}$ value was found more than 50 (97.55 and 88.91, respectively after one and three months) that indicated a good similarity 
between both the dissolution profiles. Similarly, no significant difference was observed in the drug content, mucoadhesion force, in vitro gastroretention time, integrity time, and $t_{90}$ after stability studies. Hence, the results of stability studies (Table 3) revealed that the developed formulation possessed good stability.

Table 3 - Results of stability study.

\begin{tabular}{lccc}
\hline \multirow{2}{*}{ Characteristics } & \multicolumn{3}{c}{ Duration of storage (months) } \\
\cline { 2 - 4 } & White, smooth, flat faced & White, smooth, flat faced & White, smooth, flat faced \\
\hline Physical appearance & $143.46 \pm 0.75$ & $143.48 \pm 0.73$ & $143.48 \pm 0.73$ \\
Weight variation (mg) & $99.67 \pm 1.11$ & $99.71 \pm 1.06$ & $99.66 \pm 1.09$ \\
Drug content $(\%)$ & $1.17 \pm 0.02$ & $1.17 \pm 0.01$ & $1.15 \pm 0.04$ \\
Mucoadhesion force (N) & $8.92 \pm 0.26$ & $8.90 \pm 0.18$ & $8.79 \pm 0.34$ \\
In vitro gastroretention time (h) & $9.21 \pm 0.29$ & $9.19 \pm 0.23$ & $9.15 \pm 0.13$ \\
Integrity time (h) & $7.01 \pm 0.01$ & $7.01 \pm 0.01$ & $7.01 \pm 0.01$ \\
$\mathrm{t}_{90}$ (h) & -- & 97.55 & 88.91 \\
Similarity factor $\left(f_{2}\right)$ & & & \\
\hline
\end{tabular}

* Values are the mean \pm SD; $n=3$.

\section{In vivo study}

Figure 3 showed that the formulation remained in the stomach for $1 \mathrm{~h}$ after ingestion. The intake of food did not hinder the retention of the formulation in the stomach as seen in the X-ray taken after $3 \mathrm{~h}$. The $\mathrm{X}$-ray picture of the radio- opaque formulation taken after $8 \mathrm{~h}$ showed its erosion in the stomach. The study, thus, proved the ability of the prepared formulation to remain in the stomach for prolonged period of time to satisfy the desired needs of such formulations.

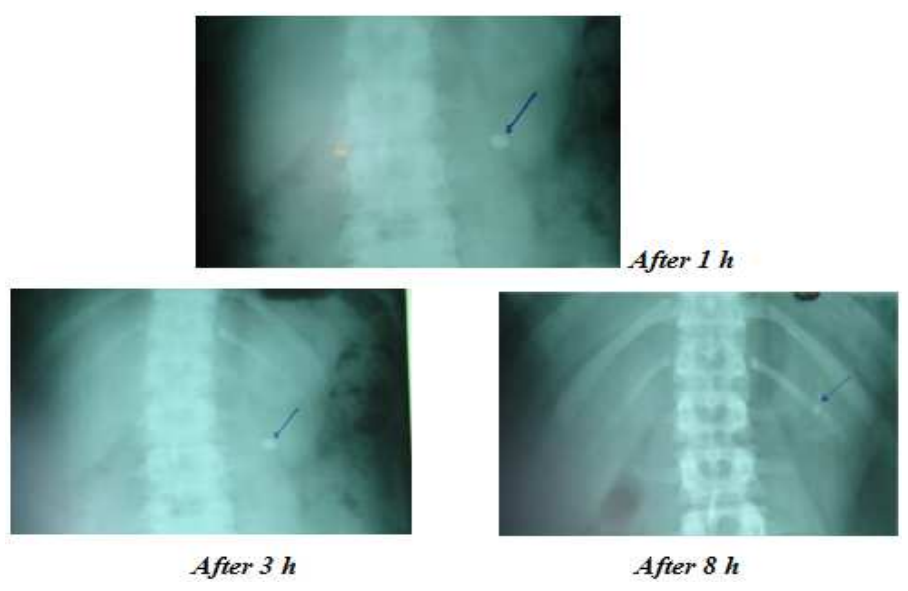

Figure 3 - X-Ray study of gastroretentive famotidine disc (Batch-FP6).

\section{CONCLUSION}

The present study showed that with the developed non-disintegrating mucoadhesive formulations, the drug release and mucoadhesion properties of mucoadhesive discs could be controlled by changing the ratio of PEO and PVP. The use of the drug with these polymers allowed preparing the discs by a simple direct compression which was cost effective. The in vitro drug release followed Korsmeyer-Peppas kinetics and the drug release mechanism was anomalous or non-Fickian type. Good gastroretentive ability was seen by in vivo study of non medicated tablet formulations by XRay method. Mucoadhesion of such developed formulations could provide a longer period of residence time, which could result in more available therapy.

\section{REFERENCES}

Ali, J.; Hasan, S.; Ali, M. (2006), Formulation and development of gastroretentive drug delivery system for ofloxacin. Methods Find. Exp. Clin. Pharmacol., $28,433-439$. 
Ali, J.; Tyagi, P.; Ahuja, A.; Baboota, S.; Hasan, S. (2007), Development and evaluation of a gastroretentive drug delivery system for the lowabsorption-window drug celecoxib., PDA J. Pharm. Sci. Technol., 61, 88-96.

Bamba, M.; Puisieux, F. (1979), Release mechanisms in gel forming sustained release preparation. Int. J. Pharm., 2, 307-315.

Basak, S.; Rahman, J.; Ramalingam, M. (2007), Design and in vitro testing of a floatable gastroretentive tablet of metformin hydrochloride. Pharmazie., 62, 145-148.

Chavanpatil, M.D.; Jain, P.; Chaudhari, S.; Shear, R.; Vavia, R.R. (2006), Novel sustained release, swellable and bioadhesive gastroretentive drug delivery system for ofloxacin, Int. J. Pharm., 316, 86-92.

Coffin, M.; Parr, A. (1995), Ranitidine solid dosage form. US Patent 5407687.

Dave, B.S.; Amin, A.F.; Patel, MM. (2004), Gastroretentive drug delivery system of ranitidine hydrochloride: formulation and in vitro evaluation, AAPS PharmSciTech., 5, e34.

Davis, S.S. (2005), Formulation strategies for absorption windows. Drug Discov. Today., 10, 249257.

Deshpande, A.A., Shah, N.H., Rhodes, C.T., Malick, W. (1997), Development of a novel controlled release system for gastric retention, Pharm. Res., 14, 815819.

Dhawan, S., Dhawan, K., Varma, M., Sinha, V.R. (2005), Application of poly (ethylene oxide) in drug delivery systems. Pharm Technol., 29, 72.

Goldsmith, J. A.; Randall, N.; Ross, S. D. (1978), Methods of expressing dissolution rate data. J. Pharm. Pharmacol., 30, 347-349.

Groning, R.; Cloer, C.; Muller, R.S. (2006), Development and in vitro evaluation of expandable gastroretentive dosage forms based on compressed collagen sponges. Pharmazie., 61, 608-612.

Gröninga, R.; Cloera, C.; Georgarakisb, M.; Müllera, R.S. (2007), Compressed collagen sponges as gastroretentive dosage forms: in vitro and in vivo studies. Eur. J.Pharm. Sci., 30, 1-6.

Harland, R. S.; Gazzaniga, A.; Sangalli, M. E., et al. (1988), Drug/polymer matrix: swelling and dissolution. Pharm. Res., 5, 488-494.

Higuchi, T. (1963), Mechanism of sustained-action medication: theoretical analysis of rate of release of solid drugs dispersed in solid matrices. J. Pharm. Sci., 52, 1145-1149.

Hixon, A. W.; Crowell, J. H. (1931), Dependence of reaction velocity upon surface and agitation. Ind. Eng. Chem., 23, 923-931.

Huang, Y.; Leobandung, W.; Foss, A.; Peppas, N.A. (2000), Molecular aspects of muco- and bioadhesion: tethered structures and site-specific surfaces. $J$. Control. Release., 65, 63-71.

Jaimini, M.; Rana, A. C.; Tanwar, Y. S. (2007), Formulation and evaluation of famotidine floating tablets. Curr. Drug Deliv., 4, 51-55.

Klausner, E.A.; Lavy, E.; Friedman, M.; Hoffman, A. (2003), Expandable gastroretentive dosage forms. J.Control. Release., 90, 143-162.

Korsmeyer, R.; Gurny, R.; Peppas, N. (1983), Mechanisms of solute release from porous hydrophilic polymers. Int. J. Pharm., 15, 25-35.
Langenbucher, F. (1972), Linearization of dissolution rate curves by the Weibull distribution. J. Pharm. Pharmacol., 24, 979-981.

Mahalingam, R.; Jasti, B.; Birudaraj, R.; Stefanidis, D.; Killion, R.; Alfredson, T.; Anne, P.; Li, X. (2009), Evaluation of Polyethylene Oxide Compacts as Gastroretentive Delivery Systems. AAPS PharmSciTech, 10, 98-103.

Marathe, P.H.; Arnold, M.E.; Meeker, J.; Greene, D.S.; Barbhaiya, R.H. (2000), Pharmacokinetics and bioavailability of a metformin/glyburide tablet administered alone and with food. J. Clin. Pharmacol., 40, 1494-1502.

Moes, A.J. (1993), Gastroretentive dosage forms. Crit. Rev. Ther. Drug Carrier. Syst., 10, 143-195.

Peppas, N. A. (1985), Analysis of Fickian and nonFickian drug release from polymers. Pharm. Acta. Helv., 60, 110-111.

Ponchel, G.; Irache, J. (1998), Specific and non-specific bioadhesive particulate systems for oral delivery to the gastrointestinal tract. Adv. Drug. Deliv. Rev., 34, 191-219.

Raval, J.A.; Patel, J.K.; Naihong, LI, Patel, M.M. (2007), Ranitidine hydrochloride floating matrix tablets based on low density powder: effects of formulation and processing parameters on drug release. Asian J. Pharm. Sci., 2, 130-142.

Reynolds, J.E.F. (1996), Martindale the Extra Pharmacopoeia, The Royal Pharmaceutical Society: London, 1218-1220.

Rouge, N.; Alle'mann, E.; Gex-fabry, M.; Balant, L.; Cole, E.T.; Buri, P.; Doelker, E. (1998), Comparative pharmacokinetic study of a floating multiple-unit capsule, a high-density multiple-unit capsule and an immediate-release tablet containing $25 \mathrm{mg}$ atenolol. Pharm. Acta Helv., 73, 81-87.

Streubel, A.; Siepmann, J.; Bodmeier, R. (2002), Floating microparticles based on low density foam powder. Int J Pharm., 241, 279-292.

Streubel, A.; Siepmann, J.; Bodmeier, R. (2003), Multiple unit gastroretentive drug delivery systems: a new preparation method for low density microparticles. J. Microencapsul., 20, 329-347.

Streubel, A.; Siepmann, J.; Bodmeier, R. (2006), Gastroretentive drug delivery systems. Expert. Opin. Drug Deliv., 3, 217-233.

Streubel, A.; Siepmann, J.; Bodmeier, R. (2006a), Drug delivery to the upper small intestine window using gastroretentive technologies. Curr. Opin. Pharmacol., 6, 501-508.

Talukder, R.; Fassihi, R. (2004), Gastroretentive delivery systems: hollow beads. Drug Dev. Ind. Pharm., 30, 405-412.

Tao, S.L.; Desai, T.A. (2005), Gastrointestinal patch systems for oral drug delivery. Drug Discov. Today., 10, 909-915.

Whitehead, L.; Fell, J.T.; Collett, J.H.; Sharma, H.L.; Smith, A.M. (1998), Floating dosage forms: an in vivo study demonstrating prolonged gastric retention. J. Control Release, 55, 3-12.

Received: January 07, 2010; Revised: September 09, 2010; Accepted: November 11, 2010. 